UJMR, Volume 6 Number 2, December, 2021, pp 135 - 141

ISSN: 2616 - 0668

https://doi.org/10.47430/ujmr.2162.019

Received: $10^{\text {th }}$ November, 2021

Accepted: $31^{\text {st }}$ December, 2021

\title{
Antibiotic Susceptibility Pattern of Bacteria Isolated from Birds Droppings in Aliero, Kebbi State, Nigeria
}

\author{
${ }^{1 *}$ Jabaka, R. D., ${ }^{1}$ Gabriel, P. O., ${ }^{2}$ Nuhu, U. D., ${ }^{3}$ Obi, Chidiebere, ${ }^{1}$ Abdulazeez, A. F. and ${ }^{4}$ Ibrahim, \\ M. A. \\ ${ }^{1}$ Department of Microbiology, Kebbi State University of Science and Technology, Aliero. \\ 2Department of Biochemistry, Kebbi State University of Science and Technology, Aliero. \\ ${ }^{3}$ Department of Microbiology, Federal University Birnin Kebbi, Nigeria. \\ ${ }^{4}$ Department of Microbiology, Umaru Musa Yar'adua University, Katsina. \\ *Corresponding Author: reginadoro1@gmail.com; phone (+2347036007818)
}

\begin{abstract}
Antibiotic resistant bacteria in bird droppings are an emerging problem of public health concern. This study investigated the antibiotic resistance pattern of some bacteria isolated from different poultry droppings. Twenty grams $(20 \mathrm{~g})$ of each sample of bird droppings were obtained from chickens, guinea fowls and turkeys. Bacteria were isolated using cultural techniques. Antibiotic susceptibility testing was carried out using disk diffusion methods against the bacterial isolates. The following Gram positive and negative bacteria were isolated; Escherichia coli (26.7\%), followed by Enterobacter aerogenes, Klebsiella pneumoniae, Shigella dysenteriae and Staphylococcus aureus (13.3\%) respectively, Salmonella spp., Pseudomonas aeruginosa, and S. epidermidis accounted for $6.7 \%$ respectively. The Gram negative bacteria showed $100 \%$ susceptibility to Streptomycin, Gentamycin and Ciprofloxacin, followed by Chloramphenicol (83.3\%), Cotrimoxazole and Perfloxacin (66.7\%), Ofloxacin $(50 \%)$ and the least was Amoxicillin (33.3\%). Moreover, the Gram negative bacteria showed highest resistance against Augmentin $(66.7 \%)$, followed by Ofloxacin (50\%), Cotrimoxazole, and Perfloxacin $(33.3 \%)$, and then least resistance to Chloramphenicol (16.7\%). Similarly, the Gram positive bacteria showed $100 \%$ susceptibility to Streptomycin, Gentamycin, Ciprofloxacin, Cefuroxime and Perfloxacin. However, the highest percentage resistance was observed against Cotrimoxazole $(50 \%)$. In conclusion, this study isolated some potentially resistant bacteria from the various samples of bird droppings. Contamination by these bird droppings may endanger the health of animals, humans and the environment as a whole. This study suggests that poultry farmers be educated about the dangers of giving medications to their birds and the significance of safe bird droppings disposal.

Keywords: Antibiotic, resistance, contamination, bird droppings and disposal.
\end{abstract}

\section{INTRODUCTION}

The increasing prevalence of multi-drug resistant bacterial strains to the available conventional medicine (antibiotics) has been a worldwide major health concern to human. However, Infectious diseases have become a major health problem globally, accounting for over 50,000 deaths every day (Lee, 2015). World Health Organization; WHO (2005), estimated that more than $70 \%$ of the pathogenic bacteria are resistant to at least one of the antibiotics commonly used to treat them.

Droppings are by-products that results from the digestion of food intake by birds, for example pigeon, guinea fowl, chicken, geese, duck and turkey among others. Bird droppings refer to the excrements of semi-solid remains of food that could not be digested in the small intestine of birds including white crystals of uric acid (George et al., 2020). Droppings (metabolic waste) from birds are discharged through the cloaca by a process known as defecation (Casali, 2003; Vlahović et al., 2002). The distinctive odour of droppings from birds is due to the bacterial action. The perceived bad odour of the droppings has been hypothesized to be a deterrent for humans, as consuming or touching it may result in sickness or infection (Curtis et al., 2004). The presence of these microorganisms in bird droppings causes various diseases in humans and fowls. These microorganisms include $E$. coli, S. species and Bacillus species and Aspergillus species that produce Aflatoxins. Most members of the family Enterobacteriaceae including S.species, E. coli, $E$. aerogenes and E. cloacae, K. pneumoniae, Proteus mirablis, and Providencia alcalifaciens also are pathogenic to humans (Horvatek et al., 2004).

Bird droppings do pose a public health risk and cause illness, particularly to the young children and farm workers when domesticated. Humans become infected by inhaling dust containing 


\section{UJMR, Volume 6 Number 2, December, 2021, pp 135 - $141 \quad$ ISSN: 2616 - 0668}

dried feces, urine, or respiratory secretions of infected birds (Chang et al., 2004). Most poultry famers in Aliero town may be creating health hazard through abuse of antibiotics in their farms and improper disposal of bird's droppings, for this reason, the aim of this research was to isolate, identify and determine the antimicrobial pattern of bacteria from different bird droppings in some selected farms in Aliero town, Kebbi State.

\section{MATERIALS AND METHODS \\ Study Area:}

This research work was carried in town of Aliero Local Government Area of Kebbi state. Aliero is a townin Kebbi State, located on the JegaSokoto route. Between latitude $12^{\circ} 16^{\prime} 42^{\prime \prime} \mathrm{N}$ and longitude $4^{\circ} 27^{\prime} 6 " \mathrm{E}$, in the south east Kebbi State. Aliero is a combination of names of two great Fulani Scholars Ali and Yero. It covers 350 $\mathrm{km}^{2}$ area and has a population of 65,973 according to the 2006 national census. The rainy seasonin Aliero is hot, oppressive, and mostly cloudy, whereas the dry season is hot humid and partly cloudy. The temperature ranges from $65^{\circ} \mathrm{F}$ to $104^{\circ} \mathrm{F}$ throughout the year, with temperature rarely falling below $61^{\circ} \mathrm{F}$ or rising over $108^{\circ} \mathrm{F}$. from March 11 to May 16 the hot season last 2.1 months, with an average daily high temperature over $101^{\circ} \mathrm{F}$ (Omoleke et al., 2018).

\section{Sample Collection}

Twenty grams $(20 \mathrm{~g})$ each of droppings from chicken, guinea fowls and turkeys from some poultry farms within Aliero metropolis, were collected in a sterile duplicate sampling bottles and labeled appropriately with the source, time and date of collection. It was transported to Microbiology Laboratory, Faculty of Life Sciences, Kebbi State University of Science and Technology, Aliero, Nigeria. The droppings were air dried for 48 hours following the method of Ebana et al. (2017).

\section{Samples processing}

Ten $(10 \mathrm{~g})$ grams of each sample was diluted in $100 \mathrm{ml}$ of normal saline, from where serial dilution was carried out using $1 \mathrm{ml}$ transfer. Eight test tubes containing $9 \mathrm{ml}$ of sterile distilled water was arranged in a test tube rack and labeled as $10^{1}, 10^{2}$ up to $10^{6}$ respectively. $1 \mathrm{ml}$ of the homogenate was added to tube $10^{1}$ it was mixed and $1 \mathrm{ml}$ was transferred from $10^{1}$ to $10^{2}$, the same procedure was repeated serially up to tube $10^{8}$ dilution factor. Exactly $0.1 \mathrm{ml}$ aliquots from the $10^{4}, 10^{5}$ and $10^{6}$ tubes were aseptically inoculated onto sterile plates of Nutrient Agar, Salmonella Shigella Agar, Eosin Methylene Blue Agar and MacConkey Agar using surface plating method of inoculation. The Nutrient agar plates were incubated at $37^{\circ} \mathrm{C}$ for 24 hours. After the incubation period, plates with distinct colonies were counted and recorded as CFU/g. The colonies were sub cultured on sterile nutrient agar plates to obtain pure isolates.

\section{Characterization and Identification of Bacterial Isolates}

The bacterial isolates were characterized on the basis of their colonial morphology, and cellular morphology through Gram's staining as described by Cheesbrough (2006). Furthermore, standard biochemical tests (Indole, Oxidase, Catalase, Urease, Coagulase, MR-VP, Citrate utilization, Motility, and Sugar fermentation) were carried out and used to describe bacterial isolates and suggestive name was giving to each isolate according to Cheesbrough (2006).

\section{Antibiotic Sensitivity Test}

Antimicrobial susceptibility was determined by disk diffusion method on Muller-Hinton agar, as described by Kirby-Bauer, in accordance with the guidelines of the Clinical and Laboratory Standards Institute (CLSI, 2019). The isolates were tested against various commercial antibiotics. Cultures were grown overnight on Nutrient Agar and incubated at $37{ }^{\circ} \mathrm{C}$. The overnight cultures were suspended in Swab stick tube containing saline solution and adjusted to a turbidity of 0.5 McFarland scale. The cultures were inoculated on Mueller Hinton Agar plates using a sterile cotton swab stick. After 30 minutes, a multiantibiotic disc was placed on the plates using sterile forceps and was incubated at $37{ }^{\circ} \mathrm{C}$ for $18-24$ hours. After the incubation period, the diameter of inhibition zones was measured and compared with interpretive chart proposed by the 'Performance Standards for Antimicrobial Disk Susceptibility Tests' which was classified as resistant, intermediate, or susceptible (CLSI, 2019).

\section{RESULTS}

Based on the result obtained, Tabled 1, revealed that dilution factor $\left(10^{1}\right)$ of sample $A$, $B, C$ and $D$ has the highest colony count of $8.0 \times 10^{3}, 4.4 \times 10^{3}, 6.2 \times 10^{3}$ and $8.0 \times 10^{3}(\mathrm{CFU} / \mathrm{g})$, followed by dilution factor $\left(10^{3}\right)$ of sample $A, B$, $C$ and $D$ with total colony count of $6.6 \times 10^{5}$, $4.2 \times 10^{5}, 4.4 \times 10^{5}$ and $6.2 \times 10^{5}$ (CFU/g), the least was found to be dilution factor $\left(10^{5}\right)$ of sample $A, B, C$ and $D$ with total colony count of $4.4 \times 10^{7}, 2.6 \times 10^{7}, 4.0 \times 10^{7}$ and $4.8 \times 10^{7}$ (CFU/g) respectively. 
UJMR, Volume 6 Number 2, December, 2021, pp 135 - $141 \quad$ ISSN: 2616 - 0668

Table 1: Total plate count of bacteria isolated from different bird droppings in some selected farms in Aliero Metropolis, Kebbi State

\begin{tabular}{lllll}
\hline Sample & $\begin{array}{l}\text { Dilution } \\
\text { factor }\end{array}$ & No. of colonies & $\begin{array}{l}\text { Bacterial colony } \\
\text { count (CFU/g) }\end{array}$ & Mean \pm SD \\
\hline A & $10^{-1}$ & 80 & $8.0 \times 10^{2}$ & \\
& $10^{-3}$ & 66 & $6.6 \times 10^{4}$ & $63.3 \pm 18.14$ \\
B & $10^{-5}$ & 44 & $4.4 \times 10^{6}$ & \\
& $10^{-1}$ & 44 & $4.4 \times 10^{2}$ & $37.3 \pm 9.86$ \\
& $10^{-3}$ & 42 & $4.2 \times 10^{4}$ & \\
C & $10^{-5}$ & 26 & $2.6 \times 10^{6}$ & $48.6 \pm 11.71$ \\
& $10^{-1}$ & 62 & $6.2 \times 10^{2}$ & \\
D & $10^{-3}$ & 44 & $4.4 \times 10^{4}$ & \\
& $10^{-5}$ & 40 & $4.0 \times 10^{6}$ & $63.3 \pm 16.04$ \\
& $10^{-1}$ & 80 & $8.0 \times 10^{2}$ & \\
& $10^{-3}$ & 62 & $6.2 \times 10^{4}$ & \\
\hline
\end{tabular}

Key: CFU/g (Colony forming unit per gram), SD (Standard deviation)

Table 2 shows bacteria isolated from different bird droppings from selected poultry farms in Aliero town, Kebbi State, Escherichia coli and $S$. aureus were isolated from all the three bird samples, while $K$. pneumoniae, $S$. dysenteriae and $E$. aerogenes were isolated from chicken and guinea fowl and $S$. epidermidis and Salmonella spp from Turkey droppings only. The Frequency and Percentage occurrence of bacteria isolated from the bird droppings showed that $E$. coli had the highest percentage of occurrence $4(26.7 \%)$ followed by $K$. pneumonia, E. aerogenes, S. dysenteriae and S. aureus 2 (13.3\%). The lowest were $S$. epidermidis, $P$. aeruginosa and $E$. aerogenes with $1(6.7 \%)$ frequency and percentage occurrence respectively.

Table 2: Frequency and Percentage of occurrence of Bacteria isolated from Birds droppings in some selected Poultry Farms in Aliero town

\begin{tabular}{llll}
\hline Poultry birds & Bacterial species & Frequency $(\mathbf{n = 1 5 )}$ & Percentage (\%) \\
\hline Chicken & E. coli & 4 & 26.7 \\
& K. pneumoniae & 2 & 13.3 \\
& S. aureus & 2 & 13.3 \\
Suinea fowl & S. dysentriae & 2 & 13.3 \\
& E. aerogenes & 2 & 13.3 \\
& K. pneumoniae & - & - \\
& E. coli & - & - \\
Turkey & E. aerogenes & - & - \\
& S. dysenteriae & - & - \\
& S. aureus & - & - \\
& S. typhimurium & 1 & 6.7 \\
& S. epidermidis & 1 & 6.7 \\
& S. aureus & - & - \\
& P. aeruginosa & 1 & 6.7 \\
& Total & 15 & 100 \\
\hline
\end{tabular}

Table 3, result showed the susceptibility profile of Gram negative bacteria. The Gram negative bacteria showed $100 \%$ susceptibility to Streptomycin, Gentamycin and Ciprofloxacin, followed by Chloramphenicol (83.3\%), Cotrimoxazole and Perfloxacin (66.7\%), Ofloxacin (50\%) and the least was Amoxicillin (33.3\%). Moreover, the Gram negative bacteria showed highest resistance against Augmentin $(66.7 \%)$, followed by Ofloxacin $(50 \%)$, Cotrimoxazole, and Perfloxacin (33.3\%), and then least resistance to Chloramphenicol $(16.7 \%)$.

UMYU Journal of Microbiology Research
Similarly, the Gram positive bacteria showed $100 \%$ susceptibility to Streptomycin, Gentamycin, Ciprofloxacin, Cefuroxime and Perfloxacin. However, the highest percentage resistance was observed against Cotrimoxazole (50\%) as presented in Table 4. 
UJMR, Volume 6 Number 2, December, 2021, pp 135 - 141

ISSN: $2616-0668$

Table 3: Percentage Susceptibility and non-Susceptibility pattern of gram negative bacteria isolated from Birds droppings in some selected Poultry Farms in Aliero Metropolis

\begin{tabular}{|c|c|c|c|c|c|c|c|c|}
\hline \multirow[b]{2}{*}{ Antibiotics } & \multicolumn{8}{|c|}{ Zones of inhibition (mm) against each isolate } \\
\hline & E. coli & P. aeruginosa & Salmonella spp & S. dysentriae & K. pneumoniae & E. aerogenes & $\%$ susceptibility & $\%$ Resistance \\
\hline $\mathrm{S}(30 \mu \mathrm{g})$ & 26.00 & 26.00 & 23.00 & 26.00 & 26.00 & 25.00 & 100 & 0.00 \\
\hline $\mathrm{CN}(10 \mu \mathrm{g})$ & 26.00 & 26.00 & 26.00 & 23.00 & 26.00 & 26.00 & 100 & 0.00 \\
\hline $\mathrm{AU}(25 \mu \mathrm{g})$ & 0.00 & 0.00 & 15.00 & 0.00 & 17.00 & 0.00 & 33.3 & 66.7 \\
\hline 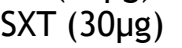 & 20.00 & 23.00 & 0.00 & 20.00 & 0.00 & 21.00 & 66.7 & 33.3 \\
\hline 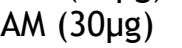 & 0.00 & 0.00 & 0.00 & 0.00 & 0.00 & 0.00 & 0.00 & 0.00 \\
\hline CPX (10ug) & 26.00 & 23.00 & 23.00 & 26.00 & 23.00 & 25.00 & 100 & 0.00 \\
\hline 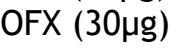 & 0.00 & 19.00 & 23.00 & 0.00 & 15.00 & 0.00 & 50 & 50 \\
\hline $\mathrm{CH}(30 \mu \mathrm{g})$ & 26.00 & 16.00 & 23.00 & 26.00 & 0.00 & 25.00 & 83.3 & 16.7 \\
\hline 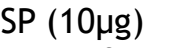 & 0.00 & 0.00 & 0.00 & 0.00 & 0.00 & 0.00 & 0.00 & 0.00 \\
\hline 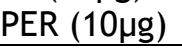 & 0.00 & 19.00 & 23.00 & 23.00 & 17.00 & 0.00 & 66.7 & 33.3 \\
\hline
\end{tabular}

Key: S (streptomycin), CN (gentamycin), AU (augmentin), SXT (Cotrimoxazole), AM (amoxacilin), CPX (ciprofloxacin), OFX (Tarivid/Ofloxacin), $\mathrm{CH}$ (chloramphenicol), SP (sparfloxacin) and PEF (perfloxacin)

Table 4: Percentage Susceptibility and non-susceptibility pattern of Gram positive bacteria isolated from Birds dropping in some selected Poultry Farms in Aliero Metropolis

\begin{tabular}{|c|c|c|c|c|}
\hline \multirow{3}{*}{ Antibiotics } & \multicolumn{3}{|c|}{ Zones of inhibition $(\mathrm{mm})$ against each isolate } & \multirow{3}{*}{ \% Resistance } \\
\hline & & & $\%$ Susceptibility & \\
\hline & S. aureus & S. epidermidis & & \\
\hline Streptomycin (30ug) & 26.00 & 26.00 & 100 & 0.00 \\
\hline Gentamicin (10ug) & 23.00 & 26.00 & 100 & 0.00 \\
\hline Ampiclox (30ug) & 0.00 & 0.00 & 0.00 & 0.00 \\
\hline Cotrimoxazole (30ug) & 21.00 & 0.00 & 50 & 50 \\
\hline Amoxacilin (30ug) & 0.00 & 0.00 & 0.00 & 0.00 \\
\hline Ciprofloxacin (10ug) & 26.00 & 26.00 & 100 & 0.00 \\
\hline Cefuroxime (20ug) & 19.00 & 22.00 & 100 & 0.00 \\
\hline Rocephin (30ug) & 0.00 & 0.00 & 0.00 & 0.00 \\
\hline Erythromycin (19ug) & 0.00 & 0.00 & 0.00 & 0.00 \\
\hline Perfloxacin (10ug) & 26.00 & 19.00 & 100 & 0.00 \\
\hline
\end{tabular}




\section{UJMR, Volume 6 Number 2, December, 2021, pp 134 - $140 \quad$ ISSN: 2616 - 0668}

DISCUSSION

Infectious diseases, threaten lives of millions of people around the world. Bacterial infection is on the increase all over the world and pandemic, poor hygiene, overcrowding and resistance to conventional antimicrobials among other factors have led to increased prevalence of bacterial infections (Oyewoleet al., 2010).

This research recorded a high bacteria colony count of $8.0 \times 10^{2}(\mathrm{CFU} / \mathrm{g})$ and the least was found to be $2.6 \times 10^{6}$ (CFU/g) from different samples of bird dropping. Likewise, high bacteria count was also reported by Adegunloye (2006) who recorded a total bacteria count isolated from bird droppings ranging from $9.35 \times 10^{7}$ to $10.58 \times 10^{7} \mathrm{CFU} / \mathrm{g}$ in broilers while $10.05 \times 10^{7} \mathrm{CFU} / \mathrm{g}$ was observed in free range chicken. It was stated that the high colony count might be attributed to constant contact between feed, poultry birds and faecal droppings (Vellinga and Van Loock, 2002). Environmental contamination or contamination from the feed or water taken in by the birds may also serve as a contributing factor.

Among various bird droppings, this study discovered potentially resistant types of bacteria. The spread of these bird droppings could endanger the health of other animals, humans, and the environment as a whole.E. coli, $P$. aeruginosa, $K$. pneumonia, $E$. aerogenes, S. typhimurium, $P$. Mirabilis, $S$. dysenteriae, S. aureus and S. epidermidis were isolated from this research. Similar species of bacteria: E. coli, E. spp., S. spp., P. spp., S. spp., and $K$. pneumonia were also isolated by Frazier and Westhoff (2003); Adegunloye, (2006); Frazier and Westhoff, (2003), a total of 10 bacterial isolates, including those of the family enterobacterioceae which can be highly pathogenic were isolated. The bacteria present in the droppings may be traced to a few sources; feed, cage or nest, normal intestinal flora, feeding water and air borne organisms.

In this study, E. coli (26.7\%) was the most frequently isolated bacteria. This is consistent with Adegunloye's findings (2006), who stated that $E$. coli are a natural inhabitant of the gut of birds but can become a problem through poor husbandry. Similarly, $K$. pneumonia, $P$. aeruginosa, S. typhi, P. mirabilis, E. aerogenes and $S$. dysenteriae have also been isolated from poultry droppings by Ngodigha and Owen (2009) and Omojowo and Omojasola (2013), it was stated that presence of these organisms is an indication to possible diseases and pollutions and may have an effect on the soil ecological balance. It is also an indication of recent faecal pollution.
Antibiotic susceptibility testing was performed on bacterial isolates with antibiotics impregnated disc which include; Gentamycin, Streptomycin, Ampiclox, Cotrimoxazole, Amoxicillin, Ciprofloxacin, Augmentin, Ofloxacin, Chloramphenicol, Perfloxacin, and Erythromycin.

This study observed a higher susceptibility of Streptomycin , Gentamycin and Ciprofloxacin antibiotics $(100 \%)$ against Gram negative bacteria, followed by Chloramphenicol (83.3\%), Cotrimoxazole and Perfloxacin (66.7\%), Ofloxacin $(50 \%)$ and the least was Amoxicillin (33.3). likewise Augmentin showed the highest resistance against Gram negative bacteria with (66.7\%), followed by Ofloxacin (50\%), Cotrimoxazole, and Perfloxacin (33.3\%), and Chloramphenicol (83.3\%). More so, Streptomycin, Gentamycin, Ciprofloxacin, Zinnacef and Perfloxacin showed the highest $(100 \%)$ susceptibility against Gram positive bacteria, the least was Cotrimoxazole $(50 \%)$. However, the highest percentage resistance was observed against Cotrimoxazole $(50 \%)$ drug whereas; Ampiclox, Amoxicillin, Rocephin and Erythromycin were the least effective antibiotics against the bacteria respectively. This result is in accordance with the findings of Ajayi and Omoya (2017) who isolated E. coli from chicken dropping with $100 \%$ resistance to some (Amoxicillin and Augmentin) antibiotics however, it was highly sensitive to Streptomycin. Similarly, Elsayed et al. (2016) isolated $P$. aeruginosa from poultry farm and showed resistance to some of the antibiotics tested (Amoxicillin 100\%, Chloramphenicol 80\% and Gentamycin 85\%). Ejeh et al., (2017), equally isolated Salmonella spp. from chicken dropping and tested with a high resistance to Amoxicillin, $100 \%$ resistance to Cotrimoxazole and showed $100 \%$ sensitivity to Ciprofloxacin. Rahimi et al. (2016) isolated Shigella spp. from turkey dropping and shown high resistance to Gentamycin $100 \%$ and Amoxicillin 84.61\%.Similarly, Mwambete and Stephen, (2015) isolated K. pneumonia from chicken dropping and observed resistance to Chloramphenicol $13.3 \%$ and Amoxicillin $46.4 \%$. More so, related findings of Hanninget al., (2012) isolated S. aureus from retailer chicken dropping which showed high resistance to Amoxicillin $100 \%$ and Erythromycin $11.7 \%$.

Good number of risk factors may be the reason behind the high prevalence and resistance of bacteria, some of the risk factors include direct exposure to outer environment during heat season, contaminated water and be contaminated feed. Misuse of antibiotics on humans, birds and other animals might have 


\section{UJMR, Volume 6 Number 2, December, 2021, pp 134 - 140 ISSN: 2616 - 0668}

attributed to the resistant strains of bacteria isolated in this research. Some of the poultry famers have the habit of drug administration to birds and animals without prescription or proper laydown rules of administration. Proper sensitization by poultry farmers, appropriate administration of drugs to birds and proper bird droppings disposal may help in reducing the circulation of resistant strains of bacteria pathogen within the environment. Similarly WHO, (2020) also stated that the main drivers of antimicrobial resistance include the misuse and overuse of antimicrobials; lack of access to clean water, sanitation and hygiene (WASH) for both humans and animals; poor infection and disease prevention and control in health-care facilities and farms; poor access to quality, affordable medicines, vaccines and diagnostics; lack of awareness and knowledge; and lack of enforcement of legislation.

REFERENCES

Adegunloye, D.V. (2006). Microorganisms Associated with Poultry Feces. Journal of Food, Agriculture and Environment4, $41-42$.

Ajayi, M. D. and Omoya, F. G. (2017). Lactobacillus agilis is an important component of the pigeon gut flora. Journal of Applied Microbiology 91, 488-491.

Casali A.K, Goulart L, Rosa e Silva L.K, Ribeiro A.M, Amaral A.A, Alves S.H, Schrank A, Meyer W, and Vainstein M.H (2003). Molecular typing of clinical and environmental Cryptococcus neoformans isolates in the Brazilian state Rio Grande do Sul. FEMS Yeast Res $3(4): 405-15$

Chang, W. N., Huang, C. R., Lei, C. B., Lee, P. Y., Chien, C. C. and Chang, H. W. (2004). Serotypes of clinical cerebrospinal fluid Cryptococcus neoformans isolates from Southern Taiwan. Japan Journal of Infectious Diseases 57, 113-115.

Cheesbrough, M. (2006). Medical Laboratory Manual for Tropical Countries.Microbiology 2, 1st edition. English Language Book Society, London.

Clapp, J. B., Bevan, R. M. and Singleton, I. (2012). Avian Urine: It's Potential as a Non-Invasive Biomonitor of Environmental Metal Exposure in Birds. 223(7):3923-3938.

Clinical and Laboratory Standards Institute (CLSI) (2019). Performance standard for antimicrobial susceptibility testing standards $M 02, M 07$, and M11. 29 ${ }^{\text {th }}$

\section{CONCLUSION}

This research has isolated some bacteria from bird droppings, thus the fact cannot be overemphasized as bird droppings if not properly handle, may pose a public health hazard to humans and the environment if their droppings accumulate in one place for long, this study also revealed that Staphylococcus aureus and E. coli were tested to be resistant to most antibiotics that was supposed to affect them. Antibiotic resistant bacteria should be closely monitored in our environment, further research is also necessary on the genetic basis of antibiotic resistant human pathogenic bacteria from different bird droppings. Therefore, poultry farmers need to be aware of the potential health risk of discharging poultry waste into the environment without treatment.

edition. Pp. 10-25

Crouch, N. M. A., Lynch, V. M. and Clarke, J. A. (2019). A re-evaluation of the chemical composition of avian urinary excreta. $J$. Ornithol. 161:17-24.

Curtis, V., Aunger, R. and Rabie, T. (2004). Evidence that disgust evolved to protect from risk of disease. Biological Science 271(4), 131-3.

Ebana, R. U. B., Edet, U. O., Ekanemesang, U. M. and Effiong, O. O. (2017). Physicochemical characterization of palm mill oil effluent and bioremediation of impacted soil. Asian Journal of Environment and Ecology. 2(1), 1-9.

EbrahimRahimi., FarzanehShirazi and FahamKhamesipour (2016). Isolation and Study of the Antibiotic Resistance Properties of Shigella Species in Meat and Meat Products. Journal of Food Processing and Preservation. 41(3), e12947.

Ejeh, R., Ghazikhanian, G. Y., Shivaprasad, H. L., Barr, B. C. and Bland, M. B. (2017). Streptococcus bovis Infection in Turkey Poults. Avian Pathology 26, 433-439.

Elsayed, B. E., Fermer, C., Lindberg, A., Saarinen, E. and Gunnarsson, A. (2016). Molecular Typing of Isolates of Clostridium perfringens from Healthy and Diseased Poultry. Veterinary Microbiology 94, 225-235.

Frazier, W. C. and Westhoff, D. C. (2003). Food Microbiology. $18^{\text {th }}$ Edition, Tata McGraw Hill, Inc, New York. 


\section{UJMR, Volume 6 Number 2, December, 2021, pp 134 - $140 \quad$ ISSN: 2616 - 0668}

GeorgeM., AnnetteS., Vincentab Hamish and Mackeyac R. (2020). An overview of anoxygenic phototrophic bacteria and their applications in environmental biotechnology for sustainable Resource recovery. Elsevier B.V. Biotechnology Reports 28.

Hanning, J., Bonnedahl, J., Waldenstro“m, J., Palmgren, H. and Olsen, B. (2012). Salmonella in Birds Migrating Through Sweden. Emerging Infectious Diseases 9, 753-755.

Horvatek, D., Gottstein, Ž., Ciglar, I., Grozdanić, H. and Mazija, E. (2004): Epidemiological study of urban pigeons. XXII Worlds Poultry Congress, Worlds Poultry Science Association- Turkish Branch, 983.

Kirby-Bauer (2021). Antibiotic Sensitivity. https: //bio.libretexts.org/@go/page/ 3483Accessed on

Lee Ventola (2015). Antibiotics resistance crises part 1: causes and threats. A peerreviewed Journal of Pharmacy and Therapeutic. Vol. 40(4). PMC 4378521-78521. PMCID: MMC 4378521, PMID: 25859123.

Mwambete, S. L. and Stephen, K. (2015). Parasites as a viability cost of natural selection in natural populations of mammals. Science 297, 2015-2018.

Ngodigha, E. M. and Owen, O. J. (2009). Evaluation of the bacteriological characteristics of Poultry litter as feedstuff for cattle. Scientific Research and Essay; 4 (3), 188-190.

Omojowo, F. and Omojasola, F. (2013). Antibiotic Resistance Pattern of Bacterial pathogens Isolated from Poultry Manure Used to Fertilize Fish Ponds in New Bussa, Nigeria. Albanian Journal of Agricultural Science; 12 (1): 81-85.

Omoleke, S.A., Alabi, O., Shuaib, F. et al. (2018). Environmental, economic and socio-cultural risk factors of recurrent seasonal epidemics of cerebrospinal meningitis in Kebbi state, northwestern Nigeria: a qualitative approach. BMC Public Health 18, 1318.

Oyewole, O. I., Owoseni, A. A. and Faboro, E. O (2010): Studies on medicinal and toxicological properties of Cajanuscajan, Ricinuscommunis and Thymus vulgaris leaf extracts. Journal of Medicinal Plants Research, 4: (19): 2004-2008.
Sieuwerts, S., De Bok F. A. M., Mols, E., De Vos W. M., Van J. E. T. and HylckamaVlieg (2008). A simple and fast method for determining colony forming units. Letters in Applied Microbiology, 47(4), 275-278.

Vellinga, A. and Van Loock, F. (2002). The Dioxin Crisis as Experiment to Determine Poultry-Related Campylobacter Enteritis. Journal of Emerging Infectious Diseases. 8(1): 1922.

Vlahovic-Palcevski Vera, BjörnWettermark, Ulf Bergman (2002). Quality of nonsteroidal anti-inflammatory drug prescribing in Croatia (Rijeka) and Sweden (Stockholm). European Journal of Clinical Pharmacology58 (3), 209-214.

Wobeser, G. (2000). Avian Botulism - Another Perspective. Journal of Wildlife Diseases 33, 181-186.

World Health Organisation. (2020). Antimicrobial resistance. https://www.who.int/newsroom/factsheets/detail/antimicrobialresistance.

World Health Organization (2002-2005). Traditional medicine strategy, 7-13 